\title{
Research on Herding Effect of Chinese Stock Market under Heterogenous Investment Structure
}

\author{
Tingting Jiang ${ }^{\mathrm{a},}{ }^{*}$, Yi Shu \\ SHU-UTS SILC Business School, Shanghai University, China \\ *, a jtt92222@163.com
}

\begin{abstract}
Keywords: Heterogeneous investment structure, Herding effect, Split share reform, Shanghai-Hong Kong Stock Connect.
\end{abstract}

\begin{abstract}
The stock market is an important component of China's financial industry, and it is also an important investor in China's investors. Studying the performance of Chinese investors in the financial market is of great significance to the healthy development of China's securities investment industry. After reviewing the literature at home and abroad, this paper finds that there are few researches on herding effects under heterogeneous investment structure. Therefore, this paper adopts the split share structure reform and Shanghai-Hong Kong Stock Connect implementation as two-time nodes and divides the Chinese stock market into three-time periods. These two major reforms have changed the equity investment structure of the Chinese stock market. Under different equity investment structures, the performance of herding effect is also different. Studying herding effect in different periods can effectively help us to better supervise and guide investors.
\end{abstract}

\section{Introduction}

Since the reform of China's split share reform, the equity structure of the stock market has undergone major changes. This system has responded to the new situation in the development of the capital market, laying a good foundation for the effective use of capital market tools to promote the development of the company, and eliminating the interests balance issue between shareholders. At the same time, this system eliminates the biggest uncertainty factor in the market for equity splits [1]. It is a major change in the history of the Chinese stock market. Since then, in November 2014, the implementation of Shanghai-Hong Kong Stock Connect once again raised the openness and maturity of China's stock market [2], which changed the structure of China's equity investment and increased the liquidity of Shanghai stocks and Hong Kong stocks. So it is of great significance.

Herding effect is widely studied as a common phenomenon in financial markets. The existing researches mainly include the fund manager's decision-making behavior and the herding effect of the overall stock market. The study of the decision-making behavior of fund managers is common in LSV [3], PCM[4] and other methods, and the research methods of herding effect on the overall stock market are such as $\mathrm{CH}[5], \mathrm{CSAD}[6]$ and so on. In addition, domestic scholars have used the CSAD method to study the herding effects of different plates in China [7], but there are few researches on herding effects under the heterogeneous investment structure. Most domestic scholars choose to directly apply foreign mature models to analyze a certain market and the perspective of the study is relatively simple. Simultaneously, there is no adjustment according to the actual situation of the domestic market, so that the comprehensiveness of study is lack. On the empirical side, on the one hand, the existing empirical research focuses on the main board, such as studying motherboard herding effect separately, or the comparison of the various components of the motherboard, or the comparison between the motherboard and the foreign market. The attention to the concept of investment structure is low, and the empirical results have not formed a clear conclusion; on the other hand, the current research on the herding effect in the securities market focuses on institutional investors, and in terms of the actual situation in China, there are numerous individual investors, and the effects of the herding effects it brings are often more significant [3]. 
Therefore, in this paper, the split share reform and the implementation of Shanghai-Hong Kong Stock Connect are taken as the time nodes, starting from different equity structures, the paper uses the cross-sectional absolute deviation method (CSAD) combined with the generalized autoregressive conditional heteroskedasticity model $(\mathrm{GARCH})$ to study the herding effect of Chinese stock market under heterogeneous ownership structure.

\section{Stock Market Investment Structure Heterogeneity and Herding Effects}

Heterogeneity in modern finance generally refers to differences in individual behavioral preferences. In this paper, it refers not only to investors' behavioral differences, but also refers to changes of the participation fund or the participants of the market. And the implementation of the split share reform and Shanghai-Hong Kong Stock Connect produces impacts to the participating funds and participants of the Chinese stock market, which has created heterogeneity in the stock market.

The essence of split share structure reform is to eliminate the differences between tradable shares and non-tradable shares. As a result, the number of tradable shares in the market has increased. At the same time, the opening of the system has attracted more investors, and the participation funds of the stock market have also increased accordingly; the implementation of Shanghai-Hong Kong Stock Connect connects the Shanghai Stock Exchange with the Hong Kong Stock Exchange each other. Some foreign capital can also invest in the Chinese stock market through the Hong Kong stock market. Both the participating funds and participants of the market have increased to some extent. The split share structure reform and Shanghai-Hong Kong Stock Connect are two very important reforms in China's stock market. The investment structure of investors before and after the reform is significantly different. Among them, the implementation of the split equity structure is a new situation that adapts to the development of the capital market, which greatly increases the degree of market liberalization in China, promotes investors' enthusiasm for investment, enriches investors' investment methods, and also solves some benefits conflict. The implementation of the Shanghai-Hong Kong Stock Connect enhances the strength of China's capital market, facilitates the opening up of the Chinese capital market, facilitates the internationalization of the Renminbi, aligns China's stock market with international standards, and takes an important step in the internationalization of the Chinese securities market.

It is not difficult to find that the development process the stock market in China is divided into three segments according to time nodes of the split share reform (2005) and the Shanghai-Hong Kong Stock Connect (2014) implementation, and the stock market investment structure in each period has its own heterogeneity.

The herding effect stems from the study of biology on the characteristics of fauna accumulation in animals. It was originally referred to as the phenomena of animal movement in groups and foraging, also known as herding or follow-up behavior [8]. It has since been widely used to describe social phenomena, which refers to the behavior that individuals in a group are consistent with that of most people and individuals intentionally imitate the behavior of most people. In the stock market, the herding effect refers that there exists the objects of learning and imitating by investors in the course of trading and they blindly imitates others, which results in the phenomenon of buying and selling the same stocks during a certain period of time. This phenomenon is widespread in China's stock market.

Compared with mature foreign capital markets, China's investors are even less rational and the herding effect is even more pronounced. Therefore, it is of great significance to use the theory of behavioral finance to study the herding effect and to analyze the influence of investors' decision-making behavior on the followers. However, in recent years, scholars at home and abroad have studied the herding effect of the stock market, which focuses on the decision-making behavior of fund managers, the herding effect of the overall stock market, or the herding effect of different sectors of the stock market, but there are few researches on herding effects under the heterogeneous investment structure of China. Therefore, this paper will study the herding effects under 
heterogeneous ownership structure, analyze the differences of herding effects in different time periods and analyze the reasons.

\section{Empirical Studies on "Herding Effect" Under Heterogeneous Investment Structure}

\subsection{Model Assumptions}

This paper presents two assumptions.

(1) Theoretically, the income of the stock market is proportional to the investment risk. When the investment risk is higher, the investment income will be relatively higher. But in fact, the stock price will also be affected by the behavior of investors. When the investors make decisions, there are often feverish emotions caused by chasing after go up and killing cheapen or high throwing and bargain hunting and so on. Therefore, this paper puts forward the following assumptions:

$\mathrm{H} 1$ : There is a herding effect in our stock market.

(II) Under the heterogenous equity investment structure, the herding effect of investors should be related to the openness of the market. With the implementation of the equity division reform and the Shanghai-Hong Kong Stock Connect, the degree of opening up of the Chinese stock market is gradually increasing. This paper proposes the following assumptions:

$\mathrm{H} 2$ : Under different heterogeneous investment structures, the herding effect level of the stock market in China is different, and the more open the market, the stronger the herding effect.

\subsection{Sources of Data}

The data needed in this paper is the market index and individual stock data. Since the implementation of the Shanghai-Hong Kong Stock Connect has no direct impact on the Shenzhen Stock Exchange, this paper mainly selects the Shanghai Composite Index and the stocks included in the Shanghai 50 as research objects. The sample data includes the daily closing prices of the Shanghai Composite Index and all the stocks included in the Shanghai Stock Exchange 50, with some modifications to the data. The data sources are all Wind database. Due to the time-to-market of the individual stocks and due to data integrity considerations, the data starting point for this paper was April 9, 2002, and the stocks with a later time to market were excluded; and the deadline was December 1, 2016. This is because Shenzhen-Hong Kong Stock Connect was formally launched on December 5 of that year. Because of the short implementation time, this paper does not study the stock market after the start of Shenzhen-Hong Kong Stock Connect.

\subsection{Empirical Analysis of "Herding Effect"}

Firstly, the ADF unit root test is performed on the data during the sample period to ensure the smoothness of the sequence.

Table 1. Parameter ADF Unit Root Test

\begin{tabular}{|c|c|c|}
\hline Test variable & t statistics & P value \\
\hline CSAD & -8.02267 & 0.0000 \\
\hline$\left|\mathrm{R}_{\mathrm{m}, \mathrm{t}}\right|$ & -10.0938 & 0.0000 \\
\hline $\mathrm{R}_{\mathrm{m}, \mathrm{t}}$ & -11.9172 & 0.0000 \\
\hline
\end{tabular}

As can be seen from the above table, the test results of the three parameters are significant, indicating that all three time series are stable.

According to the volatility of the Shanghai Composite Index's yield rate (shown in Figure 3-1), we can find that there is a fluctuating aggregation of yield rate. Therefore, using the ARCH/GARCH model is a good choice. 


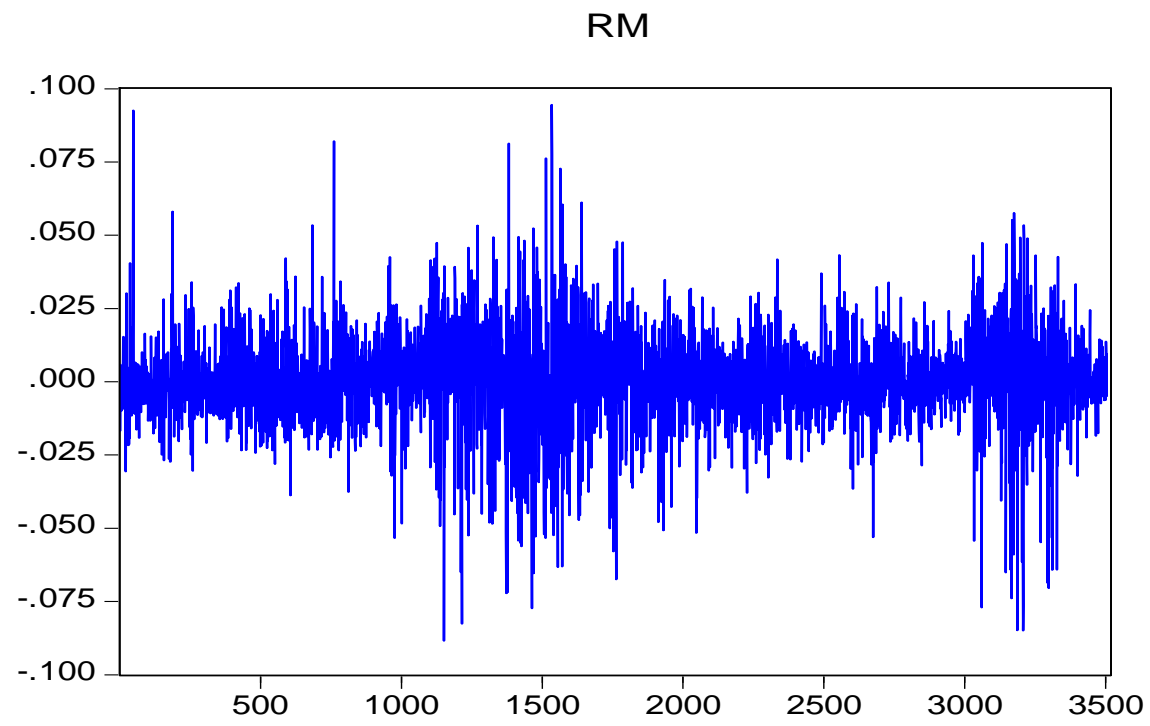

Figure 1. Shanghai Composite Index Yield Rate

In order to verify the first hypothesis, the fluctuation of stock price is related to the herding effect of investors. There is a herding effect in China's stock market. A GARCH model is established. Starting from GARCH(1,1), the order of variance and the lag order of residuals are increased in order. It is found that the lagging third-order test results are non-significant, so $\operatorname{GARCH}(2,2)$ is the most reasonable, and the regression equation is $\operatorname{CSAD}_{t}=\alpha+\gamma_{1}\left|R_{m, t}\right|+\gamma_{2}\left|R_{m, t}\right|^{2}+u_{t}$,

Get the equation expression: CSAD $=0.0254255342652 *\left|R_{m}\right|-0.659387305014 * R_{m}^{2}+$ 0.00159417095748

$\mathrm{GARCH}=5.80748723406 \mathrm{e}-09+0.3064854931 * \operatorname{RESID}(-1)^{\wedge} 2-0.263111466989 * \operatorname{RESID}(-2)^{\wedge} 2+1.1$ $775460361 * \mathrm{GARCH}(-1)-0.226286107385 * \mathrm{GARCH}(-2)$

The coefficient $R_{m}{ }^{2}$ is significantly negative, so it can be proved that there is a significant herding effect in the Chinese stock market and $\mathrm{H} 1$ can be accepted.

To verify the second hypothesis below, the herding effect is different under the heterogeneous investment structure. We divide the sample data into three segments and use the $\operatorname{GARCH}(2,2)$ model to perform the regression. The results are shown below.

Before the split share structure reform

Equation expression is: $C S A D=0.0349124622253 *\left|R_{m}\right|-0.429669621725 * R_{m}{ }^{2}+$ $0.00125067515941, \mathrm{R}$-squared $=40.64 \%$

$\mathrm{GARCH}=6.27815427624 \mathrm{e}-08+0.258657176445 * \mathrm{RESID}(-1)^{\wedge} 2-0.224531017691 * \operatorname{RESID}(-2)^{\wedge} 2+$ $0.861323033783 *$ GARCH(-1) - 0.0802519565689*GARCH(-2)

Between share reform and Shanghai-Hong Kong Stock Connect

Equation expression is $\mathrm{CSAD}=0.0192036182959 *\left|\mathrm{R}_{\mathrm{m}}\right|-0.795313309027 * \mathrm{R}_{\mathrm{m}}{ }^{2}+$ $0.00177394217735, \mathrm{R}$-squared $=33.33 \%$

GARCH=7.00301985983e-09+0.305697200274*RESID(-1)^2-0.25265925993*RESID $(-2)^{\wedge} 2+$ $1.09276200283 *$ GARCH(-1) - 0.150421369132*GARCH(-2)

After the Shanghai-Hong Kong Stock Connect

Equation expression is: $C S A D=0.0458538200413 *\left|R_{m}\right|-0.509003598142 * R_{m}{ }^{2}+$ $0.00110312367041, \mathrm{R}$-squared $=43.09 \%$

$\mathrm{GARCH}=2.86212187938 \mathrm{e}-09+0.251619053079 * \operatorname{RESID}(-1)^{\wedge} 2-0.206667878213 * \operatorname{RESID}(-2)^{\wedge} 2+$ $1.43716856103 * \mathrm{GARCH}(-1)-0.48162209895^{*} \mathrm{GARCH}(-2)$

It can be seen that in these three intervals, the coefficient of $R_{m}{ }^{2}$ is less than 0 , indicating that there are obvious herding effects in these three intervals. For ease of explanation, the coefficient of $R_{m}^{2}$ 
before the split share reform is A. The coefficient of $\mathrm{R}_{\mathrm{m}}{ }^{2}$ of the regression equation between the split share reform and Shanghai-Hong Kong Stock Connect is B. After Shanghai-Hong Kong Stock Connect, the $\mathrm{R}_{\mathrm{m}}{ }^{2}$ coefficient of the equation is C. By comparing the coefficients, it can be concluded that the herding effect after the split share structure reform is obviously stronger than that before the share structure reform. Because after the split share structure reform, the liquidity of the stock market has been greatly increased, and investors are buying and selling stocks, which is more convenient [9]. So this also supports $\mathrm{H} 2$, levels of herding effects under heterogeneous equity investment structure are different.

According to the hypothesis, the more open the market, the stronger the herding effect. However, the study found that the absolute value of $\mathrm{C}$ is less than $\mathrm{B}$, which shows that after the opening of the Shanghai-Hong Kong Stock Connect, the herding effect of the stock market is weaker than the previous one. This may be due to two reasons. First, over time, investors have gradually become more rational. Split share reform is in 2005, the Chinese investment market was only just starting to develop and the people's understanding of the market was not deep. But the implementation of the Shanghai-Hong Kong Stock Connect was in 2014. In the past year, after a long period of precipitation, the investors' understanding was far more profound than before. Second, after the implementation of the Shanghai-Hong Kong Stock Connect, Hong Kong investors can also buy and sell the stocks of the Shanghai Stock Exchange. Hong Kong's stock market is relatively mature. In many cases, Hong Kong's investors are also relatively more rational, and the "follow-up" phenomenon has weakened compared with the previous one. Therefore, the herding effect after the Shanghai-Hong Kong Stock Connect is lower than the previous one through empirical study.

The comparison between the two top 10 active stocks of Shanghai Stock Exchange and Hong Kong Stock Connect on July 31, 2015 compares the similarities and differences between Shanghai stock investors and Hong Kong stock investors.

Table 2. Top 10 active stocks of Shanghai Stock Exchange on July 31, 2015

\begin{tabular}{|c|c|c|c|}
\hline Name & Purchase amount (ten thousand yuan) & Selling amount (ten thousand yuan) & Shanghai Stock Exchange turnover (ten thousand yuan) \\
\hline Guizhou Maotai & $30,602.89$ & $5,235.24$ & $35,838.13$ \\
\hline Peace of China & $23,276.46$ & $6,093.51$ & $29,369.97$ \\
\hline Dr. Peng & $1,184.76$ & $26,890.35$ & $28,075.12$ \\
\hline China heavy Industry & $2,388.39$ & $6,223.72$ & $8,612.10$ \\
\hline Yili shares & $3,229.08$ & $4,277.22$ & $7,506.30$ \\
\hline CAAC power & $3,927.56$ & $3,483.94$ & $7,411.51$ \\
\hline Southern Airlines & $3,330.12$ & $3,5.3900$ & $6,830.50$ \\
\hline Chinese satellite & $3,032.78$ & $2,908.90$ & $5,941.68$ \\
\hline Bank Of China & $3,758.36$ & $1,897.31$ & $5,655.67$ \\
\hline Shanghai electric & $2,647.63$ & $1,983.92$ & $4,631.55$ \\
\hline
\end{tabular}

Table 3. Top 10 active stocks of Hong Kong Stocks on July 31, 2015

\begin{tabular}{|c|c|c|c|}
\hline Name & Purchase amount (ten thousand yuan) & Selling amount (ten thousand yuan) & Shanghai Stock Exchange turnover (ten thousand yuan) \\
\hline Haitong securities & $1,407.64$ & $5,072.13$ & $6,479.76$ \\
\hline Evergrande real estate & $1,954.88$ & $4,027.18$ & $5,982.06$ \\
\hline GOME & $1,535.73$ & $3,329.10$ & $4,864.84$ \\
\hline Jinsha china co., Ltd. & $4,529.59$ & 62.04 & $4,591.63$ \\
\hline Shipping transportation & $1,454.67$ & $2,427.13$ & $3,881.80$ \\
\hline High silver finance & $2,364.93$ & $1,210.98$ & $3,575.90$ \\
\hline Ali Pictures & $1,885.30$ & $1,336.52$ & $3,221.82$ \\
\hline Huishan dairy industry & $2,815.40$ & 360.05 & $3,175.45$ \\
\hline Citic Securities & 984.19 & $2,086.59$ & $3,070.78$ \\
\hline Bank of China & $1,774.20$ & $1,237.46$ & $3,011.66$ \\
\hline
\end{tabular}

Through the analysis of the active stocks of Shanghai Stock Connect, it is found that the blue chip stocks in the A share market, such as China Heavy Industry, Peace of China etc. are often sought after by investors from Hong Kong. This is mainly because most of the Hong Kong investors are 
institutional investors. The investment style is mature and steady. They prefer the low-valuation large-cap stocks and focus on value investment. Mainland investors who invest in Hong Kong stocks often prefer some well-known companies, such as Haitong Securities and Evergrande Real Estate, which have more speculative components and shorter shareholding cycles.

Therefore, from the perspective of investment targets, Hong Kong investors are more mature and more stable than mainland investors. In addition, from the perspective of the overall stock market structure, Hong Kong's stock market is more mature than the mainland. As the financial investment center in the Asia-Pacific region, its degree of freedom and openness are high, and it is hardly affected by policy factors. And the Hong Kong stock market is dominated by institutional investors and is closer to a mature market. According to statistics, among Hong Kong stock market investors, over $35 \%$ of the total transaction volume is occupied by international investors, and the proportion of all institutional investors exceeds two-thirds of the total transaction volume. are in Hong Kong. The proportion of individual investors in Hong Kong stock market is very small in terms of both quantity and impact, while individual investors are the majority in the domestic market.

After comparing the above two points, we find that a large part of the investors participating in Shanghai Stock Connect after the opening of the Shanghai-Hong Kong Stock Connect are relatively stable institutional investors. They are rational and the herding level is very low. Two cities are fully interoperable, which plays a complementary role in the market. Investors have more choices for their different types of demand, while the Shanghai and Hong Kong stock market resources have also been effectively optimized. Therefore, it is reasonable that the herding effect after Shanghai-Hong Kong Stock Connect was weaker than the previous one in the empirical results of this paper.

\section{Suggestion}

\subsection{From the Perspective of Investors}

(1) Improve their own quality. According to the statistics of Financial Net, China's retail share in 2015 was as high as $80 \%$. Retail investors are less professional than institutional investors due to various reasons. If they can learn about the relevant knowledge and risks of the financial market through professional learning and training, there will benefit the sound development of the entire stock market.

(2) Learn to follow cautiously and rationally. "The stock is risky and the investment needs to be cautious" is familiar to everyone. However, in the actual investment process, the majority of investors will inevitably lose their rationality, appear chasing after go up and killing cheapen, and follow the trend blindly. In fact, the benefits and risks are coexistent. High-yield is often accompanied by high risks. It cannot use gambling psychology to invest in stocks. Careful selection and comprehensive analysis can effectively reduce the harm caused by herding effect.

(3) Improve the investment system and avoid similar investments. There are links between institutional investors in China and similar investment ideas result in a similar investment structure. If we can further improve the investment system and innovate investment products, the herding effect between agencies will be reduced accordingly.

\subsection{From the Regulatory Perspective}

(1) Reduce market intervention and strengthen market supervision. Due to the special conditions of our country, our country's stock market has always been influenced by government forces since its establishment, and it cannot be truly market-oriented. At the same time, there are still some illegal operations in China's stock market, such as insider trading. Therefore, in order to create a fair and free investment environment, it is necessary to strengthen market supervision while reducing market intervention.

(2) Improve the information disclosure system. At present, institutions and companies are reluctant to disclose true information free of charge. A sound information disclosure system has become the top priority for the supervision and control of China's stock market. This plays an important role in effectively improving market transparency, reducing information asymmetry, and ensuring the 
accuracy and integrity of information. . Only in this way, investors can be able to buy and sell under fair conditions in order to increase the effectiveness of the market and reduce the herding effect of the market.

\section{References}

[1]. Liang Fengkai, The deficiencies of split share structure and its reform strategy. International Business Accounting, 2007. 218(2): p. 42-44.

[2]. Zhang Shiyang, Analysis of the linkage between China's Shanghai, Shenzhen and Hong Kong stock markets. Business Economics Research, 2015(1): p. 74-75.

[3]. Lakonishok, J., A. Shleifer, and R.W. Vishny, The impact of institutional trading on stock prices . Journal of Financial Economics, 1992. 32(1): p. 23-43.

[4]. Wermers, R., Mutual Fund Herding and the Impact on Stock Prices. Journal of Finance, 1999. 54(2): p. 581-622.

[5]. Christie, W.G. and R.D. Huang, Following the Pied Piper: Do Individual Returns Herd around the Market? Financial Analysts Journal, 1995. 51(4): p. 31-37.

[6]. Chang, E.C., J.W. Cheng, and A. Khorana, An examination of herd behavior in equity markets: An international perspective. Journal of Banking \& Finance, 2000. 24(10): p. 1651-1679.

[7]. Li Caifu, a Study on the Herding Effects of China's GEM Based on the CSAD Model. Technology and Market, 2013(5): p. 336-336.

[8]. Wang Hao, Analysis of stock market investment strategy based on herding Effect theory. 2009, Shanghai Jiaotong University.

[9]. Zhang Biao, Equity Division Reform and Corporate Investment: An Empirical Analysis Based on Financing Constraints Theory. Economics and Management Research, 2013(5): p. 99-111. 